\title{
The Treatment of Ringworm with Silver Nitrate Pencil in Cattle: Only One Application
}

\author{
Enis Karabulut, Ibrahim Canpolat \\ Department of Surgery, Veterinary Faculty, Firat University, Elazig, Turkey
}

\begin{abstract}
In this study, topical effectiveness of silver nitrate pencil on 33 dairy cows with ringworm (Fig. 1) was evaluated. The diameter, number and localized areas of lesions were recorded in each cattle. Later lesions were first cleansed with $70 \%$ ethyl alcohol. Skin scraping and hair specimens were collected of the margin of the lesion using a sterile scalpel blade into sterile petri dish. Lesions were scraped with sterile scalpel until bleeding slightly. Later lesion area was cauterized with a silver nitrate (nitrate d'argent) pencil (Fig. 2 ). This procedure was only once. Samples taken were treated with $10 \%$ potassium hydroxide, the samples were observed under the microscope. The cattle were followed for one month. This topical application method is easily applicable (only for once), economic (in terms of labor and cost of silver nitrate pencil ), and effective treatment (start the hair grown on the all lesions into one week) for ringworm. This method is especially suitable for organic livestock.
\end{abstract}

Keywords: Cattle, silver nitrate, ringworm, treatment, organic livestock.

\section{Introduction}

Ringworm (Dermatophytosis, trichophytosis, tinea) is keratinophitic fungal disease of skin that can be transmitted to humans. Also cause high economic losses in cattle breeding $(1,2,3,4)$. T. Verrucosum, M. gypseum, M. canis, T. equinum, T. mentagrophytes are causing fungal disease in cattle. Trichophyton verrucosum is a zoophilic species and worldwide the most commonly dermatophyte $(5,6,7)$. It can be spread by direct or indirect animal to animal contact. Dermatophytosis causes high economical losses due to decrease in meat and milk production, skin damages (8).

The incubation period is 4-6 weeks. Ringworm can occur all year round, but is seen more frequently in haused cattle during autumn and winter. Ambient temperature, sunlight and such as moisture factors plays an important role in the spread of infection $(9,10)$. Lesions are most frequently observed on the head (around the eyes and muzzle, and at the base of the ears), neck, back and perineum $(9,11,12)$. Dematophytes invade the stratum corneum of the epidermis. The scab is grayish-white and noticeably higher than the surrounding skin. Infection spreads from the center outwards and result in the circular lesion 1 to 1.5 inches in diameter. Adjacent lesions may overlap and create larger infected areas. Scrabs may fall from older lesions and leave a hairless area in the center, one that has a ring of exudate at the edge. This lesions usually resolve spontaneously in 2 to 4 months $(8,13)$.

Treatment is including different topical and systemic antifungal drugs. Systemic applications are including; ivermectin, ethylenediamine dihydriodide orally, griseofulvine orally $(11,12,14)$. Topical applications are including; thiabendazole was made in glycerine, tincture of iodine, $1 \%$ tioconazole, $10 \%$ enilconazole, propolis ointment, Whitfield's ointment, propolis and Whitfield's ointment, miconazole ointments, garlic solution, zinc oxide, salicylic acid + benzoic acid + sulfur + iodine and vaseline combination $(4,5,15,16,17,18,19,20)$. Topical applications should be made 3-4 times. Another an application is vaccination $(21,22,23)$. The most of vaccines prepared from Trichophyton verrucosum are live monovalent vaccines $(10)$.

In the present study, the effectiveness of silver nitrate pencil by topical application on the treatment of ringworm was evaluated.

\section{Material and Methods}

In this study, topical effectiveness of silver nitrate pencil on 33 dairy cows with ringworm (Fig. 1) was evaluated. The diameter, number and localized areas of lesions were recorded in each cattle. Later lesions were first cleansed with $70 \%$ ethyl alcohol. Skin scraping and hair specimens were collected of the margin of the lesion using a sterile scalpel blade into sterile petri dish. Lesions were scraped with sterile scalpel until bleeding slightly. Later lesion area was cauterized with a silver nitrate (nitrate d'argent) pencil (Fig. 2). This procedure was only once. Samples taken were treated with $10 \%$ potassium hydroxide, the samples were observed under the microscope. The cattle were followed for one month. 


\section{Result and Discussion}

The average Diameter of lesions 1-6 cm and the average number of lesions 6 was observed. The skin of affected dairy cows showed grayish-white, circumscribed, circular, raised lesions. The lesions were most commonly found on the head (around the muzzle and eyes), neck area. It was isolated Tricophyton verrucosum spores in the samples taken from cattle. The application of silver nitrate a day later occurred thin crust on the lesion (Fig. 3A). Started the hair grown on the lesion into 7-10 days (Fig. 3B). Complete recovery was observed within a month.

It is reported that application of the medication directly onto the lesion. Medication cannot penetrate the crusts; the crusts should be removed by scraping or brushing. Lesion should be treated at least twice, three to five days apart $(15,16,24)$. In present study, crusts were removed by scraping, later silver nitrate pencil application was made only for once. It is more advantageous in terms of the labor force compared to other topical applications.

The chemical cauterization effect of silver nitrate on warts and wounds have been noted (21). This study showed that silver nitrate pencil be used as a topical treatment of ringworm.

Chemically synthesized veterinary medical preparations or antibiotics no used for prevention of disease at organic livestock (25). So silver nitrate pencil can be used in ringworm treatment at organic livestock.

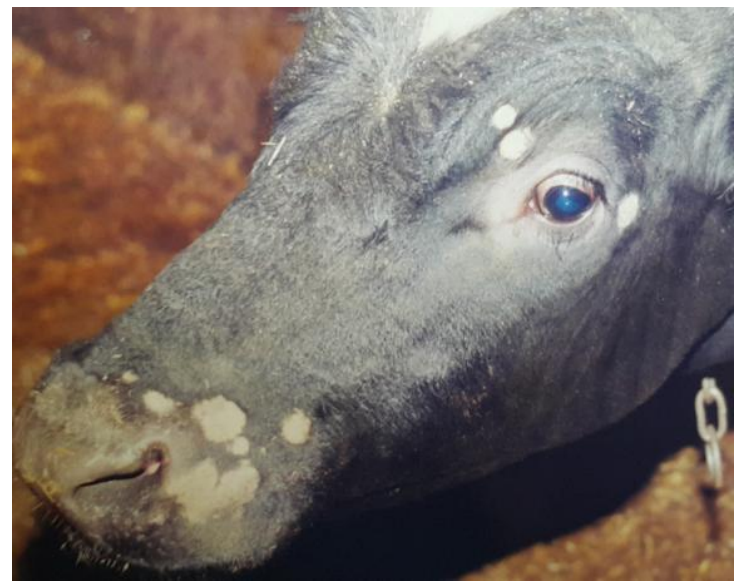

Figure 1: Circular, circumscribed, grayish-white hairless areas at muzzle and around eye.

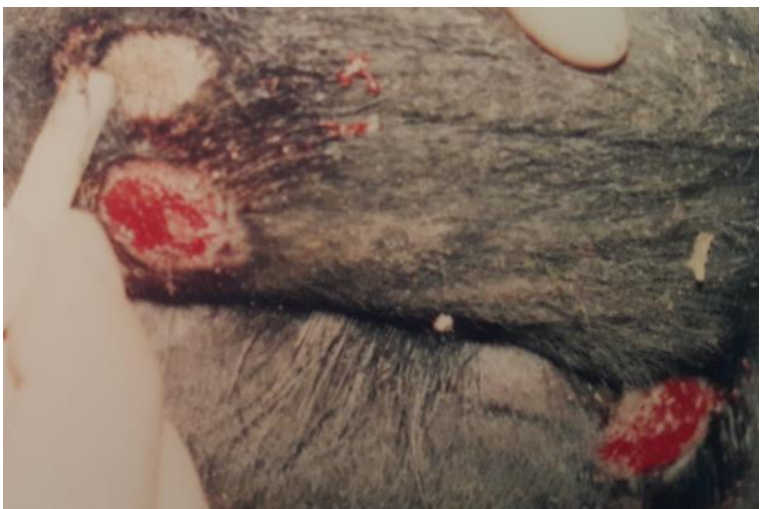

Figure 2: Application of silver nitrate pencil on scraped lesion.

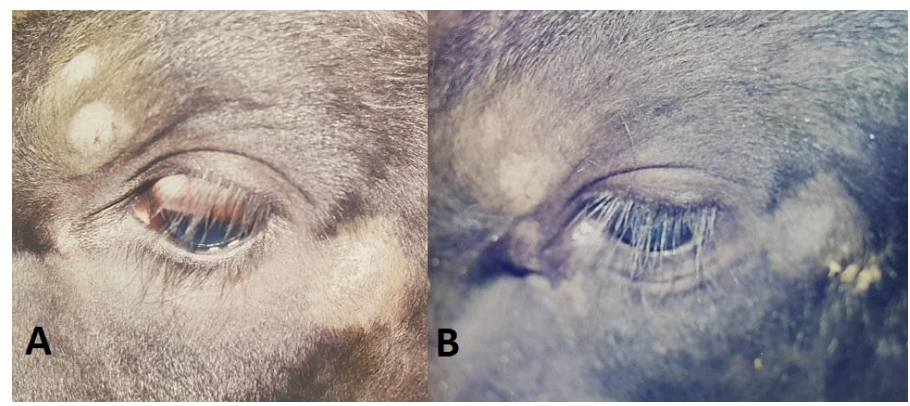

Figure 3: The application of silver nitrate one day later occurred thin crust on the lesion (A). Started the hair grown on the lesion into one week (B). 


\section{Conclusion}

This topical application method is easily applicable (only for once), economic ( in terms of labor and cost of silver nitrate pencil ), and effective treatment ( start the hair grown on the all lesions into one week ) for ringworm. This method is especially suitable for organic livestock.

\section{References}

[1] E. Atakisi, M. Karapehlivan, O. Atakisi, T. Kontas and S. Marasli, Adenosine deaminase and biochemical liver function tests in the dermatophytic cattle, Bull Vet Inst Pulawy, 50, 2006, 481-483.

[2] R. Chermette, L. Ferreiro and J. Guillot, Dermatophytoses in animals, Mycopathologia, 166, 2008, 385-405.

[3] A. Rybnikar, J. Kuja, J. Petras and V. Vrzal, Effect of antibiotic and sulphonamide treatment on the development of postvaccination immunity to trichophytosis in cattle, Acta Vet. Brno, 60, 1991, 351-356.

[4] F.K. Al-Ani, F.A. Younes and O.F. Al-Rawashdeh, Ringworm infection in cattle and horses in Jordan, Acta Vet. Brno, 71, 2001, 55-60.

[5] E.M. El-Diasty, M.A. Ahmed, N. Okasha, S.F. Mansour, S.I. El-Dek, H.M.A. El-Khalek and M.H. Youssif, Antifungal activity of zinc oxide nanoparticles against dermatophytic lesions of cattle, Romanian J. Biophys, 23(3), 2013, 191-202.

[6] J. Akbarmehr, The prevalence of cattle ringworm in native dairy farms of Sarab city (Easy Azarbayjan province), Iran, African Journal of Microbiology Research, 5(11), 2011, 1268-1271.

[7] F.J. Cabanes, Dermatophytes in domestic animals, Revista Iberoamericana de Micología Apdo, 699, E-48080 Bilbao (Spain), 2000, 104-108.

[8] G.H. Jameel, A.A. Ahmed, O.K. Jalil and W.S. Dawood, Ivermectin activity in treatment of cattle dermatophytosis, Diyala Agricultural Sciences Journal, 7(1), 2015, 30-40.

[9] Y. Ozkanlar, M.S. Aktas and E. Kirecci, Mycozoonosis associated with ringworm of calves in Erzurum province, Turkey, Kafkas Univ. Vet. Fak. Derg, 15 (1), 2009, 141-144.

[10] G.Gokce, M. Sahin, K. Irmak, S. Otlu, F. Aydin and O. Genc, Prophylactic and therapeutic use of vaccine against ricophytosis in cattle, Kafkas Univ. Vet. Fak. Derg. 5 (1), 1999, 81-86.

[11] Y. Cam, K.S. Gumussoy, M. Kibar, N. Apaydin and O.Atalay, Efficacy of ethylenediamine dihydriodide for the treatment of ringworm in cattle, Veterinary Record, 160(3), 2007, 408-410.

[12] G.H. Jameel, T.R. Minnat, A.A. Humadi and A.İ.A. Al-Ezzy, Hematological and Histopathological effects of ivermectin in treatment of ovine dermatophytosis in Diyala province-Iraq, International Journal of Science and Research, 3(11), 2014, 13891394.

[13] Anonymous, The BSAVA's Scientific Committee, Ringworm (dermatophytosis), Journal of Small Animal Practice, 39(7), 1998, 362-366.

[14] A.H. Kirmizigul, E. Gokce, M. Sahin, S. Kiziltepe, F. Buyuk and E.E Erkilic, Clinical Effectiveness of Ivermectin on Bovine Dermatophytosis, Kafkas Univ. Vet. Fak. Derg, 18 (3), 2012, 523-526.

[15] V.S. Pandey, Effect of Thiabendazole and tincture of iodine on cattle ringworm caused by trichophyton verrucosum. Trop. Anim. Hith Prod, 11, 1979, 175-178.

[16] A.H. Kirmizigul, E. Gokce, F. Buyuk, E.E Erkilic, O. Celebi, A. Gulmez and M. Citil, Effectiveness of the local application of $1 \%$ tioconazole in the treatment of bovine dermatophytosis, Kafkas Univ. Vet. Fak. Derg. 19 (Suppl-A), 2013, A191-A194.

[17] A.H. Kirmizigul, E. Gokce, Z. Ozyildiz, F. Buyuk and M. Sahin, Topical use of enilconazole (10\%) in the treatment of bovine dermatophytosis: Clinical,mycological, and histopatological findings, Kafkas Univ. Vet. Fak. Derg. 15 (2), $2009,273-277$.

[18] Y. Cam, A.N. Koc, S. Silici, V. Gunes, H. Buldu, A.C. Onmaz and F.F. Kasap, Treatment of dermatophytosis in young cattle with propolis and Whitfield's ointment, Veterinary Record, 165(7), 2009, 57-58.

[19] E.S. Swai and P.N. Sanka, Bovine dermatophytosis caused by trychophyton verrucosum: A case report, Vet. World, 5(5), 2012, 297-300.

[20] M. Pal, Diagnosis and management of trichophyton verrucosum infection in ruminants-A report of 4 animals, Intas Polivet, 16(1), 2015, 464-466.

[21] S, Yazar and E.Basaran, Efficacy of silver nitrate pencils in the treatment of common warts, , 21(5), 1994, 329-333.

[22] A. Rybnikar, V. Vrzal and J.Chumela. Vaccination of young calves against trichophytosis, Acta Vet Brno, 62, $1993,55-61$.

[23] A. Lund, A.M. Bratberg, B. Naess and R. Gudding, Control of bovine ringworm by vaccination in Norway, Veterinary Immunology and Immunopathology, 158, 2014, 37-45.

[24] R.L. Morter, J. Callahan, Ringworm of cattle, https://www.extension.purdue.edu/extmedia/VY/VY-56.html date of access, 15.08.2016.

[25] T. Ayyildiz and H. Tosun,C.B.U, Organic dairy farming, Journal of Science, 8(1), 2012, 47-60. 